\section{Relationship between the Physical Properties and Perceived Saltiness of Various Surimi Gels Prepared by Different Setting Conditions}

\author{
Thi My Hanh Tran ${ }^{1,3}$, Kaoru Kohyama ${ }^{2}$, Natsuki Watanabe ${ }^{1}$, Kazufumi Osako $^{1}$ and Emiko Okazaki ${ }^{{ }^{*}}$ \\ ${ }^{1}$ Department of Food Science and Technology, Tokyo University of Marine Science and Technology, Japan \\ ${ }^{2}$ Food Research Institute, National Agriculture and Food Research Organization, Japan \\ ${ }^{3}$ Faculty of Food Technology, Nha Trang University, Vietnam
}

*Corresponding author: Emiko Okazaki, Department of Food Science and Technology, Tokyo University of Marine Science and Technology, Konan 4-5-7, Minato-ku, Tokyo 108-8477, Japan, Tel: +81-3-5463-0618; Fax: +81-3-5463-0618; E-mail: eokazaki@kaiyodai.ac.jp

Received date: March 14, 2017; Accepted date: April 11, 2017; Published date: April 20, 2017

Copyright: ( 2017 Tran TMH, et al. This is an open-access article distributed under the terms of the Creative Commons Attribution License, which permits unrestricted use, distribution, and reproduction in any medium, provided the original author and source are credited.

\begin{abstract}
Salt intake is an important concern for health reasons and saltiness is affected not only by content of food, but also by the texture. Surimi-based products, such as kamaboko, are elastic gels with approximately $2 \% \mathrm{NaCl}$; despite recent concerns among Japanese consumers regarding high-salt foods, little is known about the relationship between saltiness and texture in these products. This study was aimed to clarify the relationship between saltiness and texture using heat-induced surimi gels as a model of surimi-based product. Various types of heat-induced gels with different physical properties were prepared from surimi and washed surimi by two-step heating with different setting (preheating) times at $30^{\circ} \mathrm{C}$. Washed surimi was prepared to remove the additives, because the additives were thought to affect the taste of surimi gel. The physical properties of heat-induced gels were characterized by puncture breaking strength and expressible water. The perceived saltiness of the heat-induced surimi gels was evaluated with fixed number of chewing. Next, to improve the demerit of this method, the perceived saltiness of the washed surimi gels was evaluated by free chewing conditions. The perceived saltiness after fixed number of chewing and the maximum saltiness intensity during free chewing was evaluated using sensory tests by comparisons with salt solutions of known concentrations. The physical properties of heat-induced gels differed considerably depending on the salt content and heating conditions. A longer setting time was associated with a higher breaking force and lower expressible water, regardless of salt content. On the other hand, perceived saltiness depended on the $\mathrm{NaCl}$ concentration, but not greatly influenced by the physical properties of the gels prepared from both surimi and washed surimi. The perceived saltiness of all gels tested was less than $1 / 3$ of solution with the same $\mathrm{NaCl}$ concentration. The maximum saltiness intensity did not correlate with breaking force, breaking strain and expressible water of heat-induced gels. From these results, it was suggested that the difference in physical properties derived by setting did not affect the relative saltiness intensity of gels to $\mathrm{NaCl}$ solution during consumption of surimi gels.
\end{abstract}

Keywords: Surimi-based products; Saltiness; Physical property; Setting; Heating condition; Sensory evaluation

\section{Introduction}

Demand for reduced-salt food products by health-conscious consumers has recently increased owing to associations between excessive salt intake and a range of diseases, e.g., hypertension and kidney diseases [1-3]. According to guidelines established by the $\mathrm{WHO}$, the recommended salt intake is less than $5 \mathrm{~g}$ per day [4]. The United State recommends a salt intake of 3.75-5.75 g per day [5], the other countries set higher values of $6 \mathrm{~g}$ in the United Kingdom [6], $6 \mathrm{~g}$ in Australia [7], and $8 \mathrm{~g}$ for men and $7 \mathrm{~g}$ for woman is recommended in Japan [8]. Japanese recommendation is relatively higher than other countries, because many Japanese food are based on salty taste, and the actual salt intake per day is higher than those recommended.

On the other hand, approximately $1.5-2.5 \% \mathrm{NaCl}$ is added to surimi for the production of surimi-based products, such as kamaboko [9], to solubilize the myofibrillar protein of fish meat and promote gelation to obtain the special elastic texture. Despite this, it is said that consumers do not perceive high saltiness in these products and therefore may unintentionally consume excess salt.
In general, flavor intensity is thought to be affected not only by the content of ingredients, but also by the texture of food. Sensory tests of various food gels, including egg whites [10,11], agar [12-14], and gelatin [15] at various concentrations, have suggested that sweetness is relatively weak in hard gels and strong in soft gels. It is possible that surimi-based products exhibit a similar texture-dependent pattern. However, little is known about the relationship between the saltiness and physical properties of these products. For these reasons, not only the salt concentration contained in the surimi-based products but also the factors which affect the perceived saltiness should be considered for properly controlling the salt intake of consumers and for manufacturing of reduced salt products.

The physical properties of surimi gels are affected by the heating conditions, such as temperature, time, and the combination of heating at different temperatures $[16,17]$. The phenomenon of setting (suwari) in the manufacturing process of surimi-based products is well known. Setting is a gelation of myofibrillar protein mainly based on enzymatic crosslinking reaction caused by heating salt-ground fish meat at a relatively low temperature (around $30^{\circ} \mathrm{C}$ ), and the intensity of the reaction varies with temperature and time. By subsequently heating at high temperature around $90^{\circ} \mathrm{C}$, a higher gel strength is obtained than when directly heated without setting. For this reason, a two-steps 
heating method is widely used for manufacturing of surimi-based products.

In previous studies on the relationship between texture and taste of foods concentrations of texture modifier such as agar, starch, etc. were changed in order to control the texture [10-15]. On the other hand, in the case of surimi gel, various types of heat-induced gels with different textures can be obtained from the same material, without additives. Therefore, surimi gel was thought to be suitable for investigations of the relationship between texture and taste.

Accordingly, in this study, the relationship between the physical properties and saltiness was examined using heat-induced surimi gels prepared by different setting (preheating at $30^{\circ} \mathrm{C}$ ) times from the same materials. As materials, both surimi and washed surimi were used. Surimi generally contains $5-8 \%$ of saccharide such as sucrose and/or sorbitol, and $0.2-0.3 \%$ polyphosphate, which are used to prevent protein denaturation during frozen storage. In this study, washed surimi was prepared to remove the additives, because the additives were thought to affect to the taste of surimi gel. Further, to evaluate the perceived saltiness, the heat-induced surimi gels was evaluated with fixed number of chewing, and next, to improve the demerit of this method, the saltiness efficiency of the washed surimi gels was evaluated by free chewing conditions.

\section{Materials and Methods}

\section{Preparation of heat-induced surimi gels}

Frozen Alaska pollock surimi (FA grade, Maruha Nichiro Corporation, Tokyo, Japan) blocks $(10 \mathrm{~kg}$ ) were cut into portions of approximately $500 \mathrm{~g}$, vacuum packed, and kept at $-30^{\circ} \mathrm{C}$ until use.

Frozen surimi was thawed overnight, cut into small pieces, and chopped with $20 \%(\mathrm{w} / \mathrm{w})$ ion exchanged water and $\mathrm{NaCl}(1 \%, 2 \%$, and $3 \% \mathrm{w} / \mathrm{w}$ ) until it became a viscous paste using a refrigerated cutter (Model UMC 5E; Stephan Machinery Co., Hameln, Germany) under vacuum conditions. The temperature was maintained at below $10^{\circ} \mathrm{C}$ Surimi paste was stuffed into a polyvinylidene chloride casing tube (30 $\mathrm{cm}$ in length and $23 \mathrm{~mm}$ in diameter; Kureha Chemical Industry Co., Ltd., Nishiki, Japan) and incubated in water baths for setting at $30^{\circ} \mathrm{C}$ for $0-240 \mathrm{~min}$, followed by a second heating at $90^{\circ} \mathrm{C}$ for $30 \mathrm{~min}$. After heating, the gel was cooled immediately in ice water overnight, and physical properties were measured and a sensory evaluation was performed at $25^{\circ} \mathrm{C}$.

\section{Preparation of heat-induced gels from washed surimi}

Frozen Alaska pollock surimi was thawed overnight, cut into small pieces (about $1 \times 1 \times 1 \mathrm{~cm}^{3}$ ), chopped using a refrigerated cutter (Model UMC 5E) and stirred with 10 volumes of cold $0.4 \% \mathrm{NaCl}$ solution $\left(4.5^{\circ} \mathrm{C}\right)$ for $10 \mathrm{~min}$. After it was maintained at $4.5^{\circ} \mathrm{C}$ for 30 min, the mixture was centrifuged at $12,000 \times g$ for $15 \mathrm{~min}$ at $0^{\circ} \mathrm{C}$ and the precipitate was collected. This procedure was repeated twice. The precipitate was collected, the water content was adjusted to $87 \%(\mathrm{w} / \mathrm{w})$, and $\mathrm{NaCl}$ was added $(1 \%, 2 \%$, and $3 \%(\mathrm{w} / \mathrm{w})$ final concentrations) in a refrigerated vacuum cutter operated at $300 \mathrm{rpm}$ for $4 \mathrm{~min}$. The temperature was maintained below $10^{\circ} \mathrm{C}$. The heat-induced gel from the salt-ground paste was prepared following the same procedure used for the heat-induced surimi gel.

\section{Proximate composition}

Moisture and crude ash contents were analyzed according to the methods of AOAC [18]. Total nitrogen content was determined by the Kjeldahl method [19] and a nitrogen conversion factor of 6.25 was used for calculating the protein content. Crude lipid was extracted according to the method of Folch et al. [20]. The crude carbohydrate content was obtained by subtracting the total composition ratios (\%) of other chemical components from 100\%. Sucrose and sorbitol in washed surimi were determined by UV method and colorimetric method, respectively $[21,22]$.

\section{Puncture test}

Heat-induced gel samples with $23 \mathrm{~mm}$-diameter were cut into cylinders of $25 \mathrm{~mm}$-height. A center part of the cylindrical gels were compressed with a spherical plunger (5 mm-diameter) at a constant rate of $1 \mathrm{~mm} / \mathrm{s}$ at $25^{\circ} \mathrm{C}$ until breaking using a rheometer (Rheoner II, RE2-33005B; Yamaden Co., Ltd, Tokyo, Japan). Breaking force (g) and breaking strain $(\mathrm{mm})$ were determined. Ten replicate measurements were conducted and the highest and lowest values were omitted $[17,23,24]$.

\section{Measurement of water holding capacity}

The water holding capacity of the gel was determined by the amount of expressible water. Cylindrical surimi gels were cut into thin slices weighing approximately $1 \mathrm{~g}(1.000 \pm 0.025 \mathrm{~g} ; 23 \mathrm{~mm}$ in diameter and about $0.25 \mathrm{~mm}$ in thickness). The slices were placed between two types of filter papers (No. 4A and No. 2A; Whatman International Ltd., Maidstone, UK) both above and below the sample (No. 4A on the inner side, No. $2 \mathrm{~A}$ on the outer side). The samples were pressed under a fixed pressure $\left(9.8 \times 10^{5} \mathrm{~Pa}\right)$ for $20 \mathrm{~s}$. Expressible water was calculated according to the following formula [17].

$$
\begin{aligned}
& \text { Expressible water }(\%) \\
& =\frac{\text { pre-pressed weight }(\mathrm{g})-\text { after-pressed weight }(\mathrm{g})}{\text { pre-pressed weight }(\mathrm{g})} \times 100
\end{aligned}
$$

and, the average value of four replicate measurements was obtained.

\section{Sensory evaluation}

Sensory analyses of gels were conducted by students from the Food Processing Laboratory of TUMSAT. Twenty panelists were selected and trained according to ISO 8586-2012 [25]. The sensory evaluation was performed in individual places in test room at $20 \pm 2^{\circ} \mathrm{C}$. Gel samples were cut into fixed sizes and presented a piece in a random order to every panelist. Reference solutions with different $\mathrm{NaCl}$ concentrations were prepared. The panelists evaluated the perceived saltiness of samples compared to that of reference solution and assigned scores after chewing the samples as described below. The saltiness efficiency of the surimi gels were evaluated by "Evaluation 1" with fixed number of chewing. Next, to improve the demerit of this method, the saltiness efficiency of the washed surimi gels were evaluated by "Evaluation 2" under free chewing conditions.

Evaluation 1 (Fixed number of chewing): Each panelist evaluated the perceived saltiness of a about $4 \mathrm{~g}$ sample $(23 \mathrm{~mm}$ in diameter and $10 \mathrm{~mm}$ in height) with three-digit codes without information about the sample) after fixed number of chews (10 or 20 times) and compared it 
with the saltiness of 10 reference solutions $(0.220-0.519 \%(\mathrm{w} / \mathrm{w})$, $0.350-0.825 \%(\mathrm{w} / \mathrm{w})$, and $0.450-1.061 \%(\mathrm{w} / \mathrm{w}) \mathrm{NaCl}$ solutions for the evaluation of surimi gels with $1 \%, 2 \%$, and $3 \% \mathrm{NaCl}$, respectively). Four samples were evaluated in a session and one session lasted for about $15 \mathrm{~min}$. The saltiness efficiency ratio was calculated as the ratio of the concentration of salt solution perceived as having an equivalent saltiness to that of the sample gel divided by the real salt concentration of the sample $(1,2$ or $3 \%(w / w))$.

Evaluation 2 (Free chewing): Gel samples from washed surimi were cut into $1.00 \pm 0.05 \mathrm{~g}(23 \mathrm{~mm}$ in diameter and $10 \mathrm{~mm}$ in height, divided into 4 small pieces). Samples with three-digit codes without information about the sample were presented in a random order with 2 replicates to every panelist. Each panelist was asked to insert a sample in the mouth and evaluated the maximum saltiness of every sample after chewing in a normal manner without indicating number of chews using a ten-point scale. Three reference solutions were used for evaluation of gels (Table 1). Four samples were evaluated in a session and the same evaluation was performed on another day (2-replicates). One session lasted for about $15 \mathrm{~min}$. A sufficiently long interval (>120 s) was set between each trial of sensory evaluation.

\begin{tabular}{|l|l|l|l|}
\hline \multirow{2}{*}{ For evaluation of surimi gel } & Score $\mathbf{0}$ & Score 5 & Score 10 \\
\cline { 2 - 4 } & \multicolumn{2}{|l|}{ Reference NaCl solutions (\% w/w) } \\
\hline $1 \%(w / w)$ & 0 & 0.322 & 0.519 \\
\hline $2 \%(w / w)$ & 0 & 0.512 & 0.825 \\
\hline $3 \%(w / w)$ & 0 & 0.659 & 1.061 \\
\hline
\end{tabular}

Table 1: Reference $\mathrm{NaCl}$ solutions for the evaluation of perceived saltiness of heat-induced surimi gels containing 1,2 and $3 \%(w / w)$ $\mathrm{NaCl}$.

The saltiness efficiency is the salt concentration of salt solution perceived as equivalent saltiness as a sample divided by the real salt concentration contained in the sample.

\section{Statistical analysis}

All instrumental determinations were performed in quadruplicate, at minimum. Data are expressed as means \pm standard deviations. Analyses of variance (ANOVA) were performed using SPSS software (SPSS 16.0 for Windows). Differences among the mean values of various treatments were measured by Duncan's multiple range test $(\mathrm{p}<0.05)$. The sensory evaluation data were analyzed using PanelCheck V.1.4.0 [26].

\section{Results and Discussion}

\section{Evaluation of perceived saltiness of heat-induced surimi gel}

Determination of heating condition of surimi gels: Prior to the experiment, the heating conditions to obtain surimi gels with "strong" and "weak" breaking properties were determined. Two-step heated gels with different breaking properties were prepared by the combination of setting at $30^{\circ} \mathrm{C}$ for $0-240 \mathrm{~min}$ and a second heating at $90^{\circ} \mathrm{C}$ for $30 \mathrm{~min}$. The breaking force of these gels is shown in Figure 1. The gel strength increased as the increase of setting time for both the setting gel and 2step heated gel. The breaking force of the 2-step heating gel with setting more than $20 \mathrm{~min}$ became greater than $500 \mathrm{~g}$. For the preparation of a "strong gel (A)" and "weak gel (B)" for subsequent analyses, two heating conditions were selected: (A) setting at $30^{\circ} \mathrm{C}$ for $60 \mathrm{~min}$ followed by $90^{\circ} \mathrm{C}$ for $30 \mathrm{~min}$ and (B) $90^{\circ} \mathrm{C}$ for $30 \mathrm{~min}$.

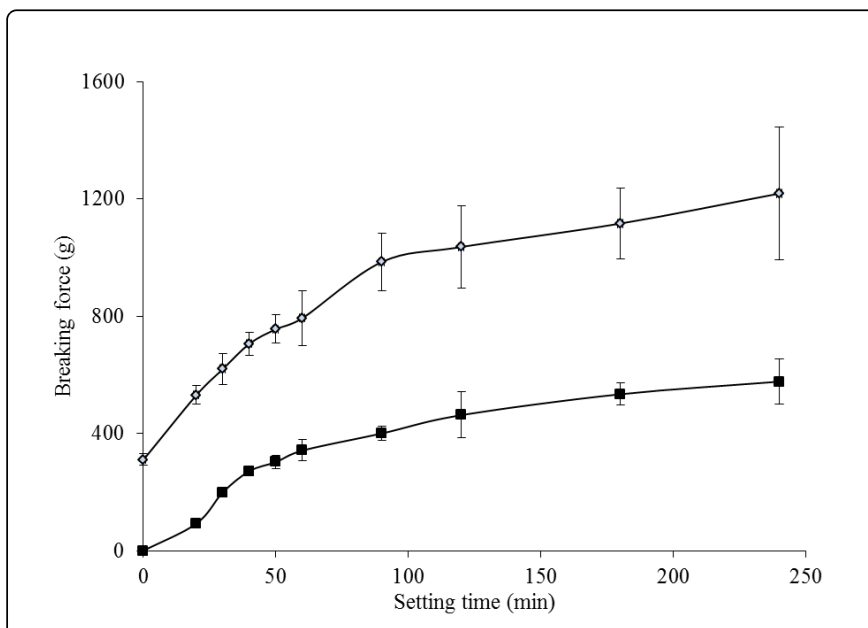

Figure 1: Temperature effects on gelation curves of heat-induced surimi gels (added $3 \%(\mathrm{w} / \mathrm{w}) \mathrm{NaCl}$ ) by setting at $30^{\circ} \mathrm{C}$ and followed by second heating at $90^{\circ} \mathrm{C}$. Means and the standard deviations of eight measurements determined below $10^{\circ} \mathrm{C}$. Closed squares: setting at $30^{\circ} \mathrm{C}$, open diamonds: Two-steps heated gel (setting at $30^{\circ} \mathrm{C}$ for $0-240 \mathrm{~min}$, followed by second heating at $90^{\circ} \mathrm{C}$ for $30 \mathrm{~min}$ ).

Physical properties of heat-induced surimi gels: The physical properties of heat-induced surimi gels (A and $\mathrm{B}$ ) with different $\mathrm{NaCl}$ concentrations are summarized in Table 2. The breaking force and breaking strain drastically increased by setting prior to heating at $90^{\circ} \mathrm{C}$, regardless of the $\mathrm{NaCl}$ content in the gels. These results close to other researches, the breaking force of Alaska Pollock surimi at $30^{\circ} \mathrm{C}$ for 30 min incubation was significantly higher $(\mathrm{p}<0.05)$ than that of no incubation (direct heating at $85^{\circ} \mathrm{C}$ for $30 \mathrm{~min}$ ). This indicates that the 'suwari' (gel setting) is strongest when incubated at $30^{\circ} \mathrm{C}$ for surimi from Alaska Pollock [17]. Similar phenomena have been observed in other studies $[27,28]$. The unique texture obtained by setting is thought to mainly result from the enzymatically catalyzed formation of nondisulfide covalent bonds between protein molecules [17]. For the surimi gel, salt must be added to solubilize the myofibrillar protein to form actomyosin, which form the network structure of the heatinduced gel and contribute the elastic texture [17,29]. In general, gels prepared by 2 -step heating have higher breaking force than directly heated gels [30,31].

\begin{tabular}{|l|l|l|l|l|}
\hline \multirow{2}{*}{$\mathbf{N a C l}$} & & \multicolumn{1}{l|}{$\mathbf{1 \%}$} & $\mathbf{2} \%$ & $\mathbf{3} \%$ \\
\hline \multirow{2}{*}{ Breaking force $(\mathrm{g})$} & $\mathrm{A}$ & $1048 \pm 61^{\mathrm{a}}$ & $1292 \pm 86^{\mathrm{c}}$ & $1313 \pm 74^{\mathrm{e}}$ \\
\cline { 2 - 5 } & B & $251 \pm 14^{\mathrm{b}}$ & $271 \pm 22^{\mathrm{d}}$ & $310 \pm 19^{\mathrm{f}}$ \\
\hline \multirow{2}{*}{ Breaking strain (mm) } & A & $15.2 \pm 0.4^{\mathrm{a}}$ & $17.9 \pm 0.2^{\mathrm{c}}$ & $18.6 \pm 0.2^{\mathrm{e}}$ \\
\cline { 2 - 5 } & B & $7.4 \pm 0.3^{\mathrm{b}}$ & $9.6 \pm 0.4^{\mathrm{d}}$ & $11.7 \pm 0.2^{\mathrm{f}}$ \\
\hline
\end{tabular}

Table 2: Breaking properties of heat-induced surimi gels prepared by different setting time and $\mathrm{NaCl}$ addition. (A) and (B): Refer to the footnote in Figure 2. Data are expressed as mean \pm standard deviation $(n=8)$. Different alphabetical letters within a column indicate statistical differences $(\mathrm{p}<0.05)$. 
Citation: Tran TMH, Kohyama K, Watanabe N, Osako K, Okazaki E (2017) Relationship between the Physical Properties and Perceived Saltiness of Various Surimi Gels Prepared by Different Setting Conditions. J Exp Food Chem 3: 124. doi:10.4172/2472-0542.1000124

Page 4 of 7

Perceived saltiness and saltiness efficiency ratio of heat-induced surimi gels: With respect to the sensory evaluation, it was necessary to determine the number of chews for each gel because perceived saltiness may be affected by chewing conditions. A preliminary test revealed that the gel with a higher breaking force (A with $3 \% \mathrm{NaCl}$ ) needed higher number of chews of $25.1 \pm 3.5$, which was longer than that of the gel with a weaker breaking force (B with $3 \% \mathrm{NaCl})(17.1 \pm$ 2.7). Other study suggests that chewing force and chewing movements may be strongly influenced by the texture of food [32]. Therefore, in this sensory test, the saltiness levels after chewing 10 and 20 times were assumed to indicate the saltiness at the "early stage of mastication" and later stage at the "just before swallowing," respectively.
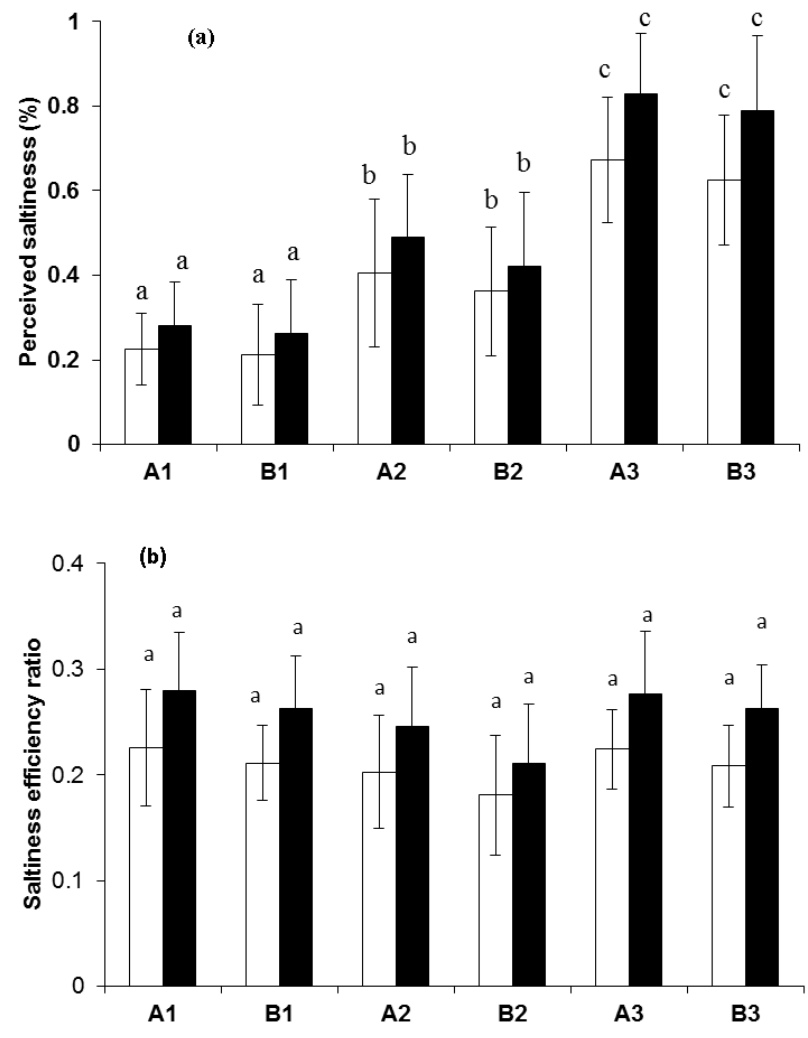

Figure 2: Perceived saltiness score (a) and saltiness efficiency ratio (b) of gel samples evaluated after chew for 10 and 20 times. Perceived saltiness is expressed as $\mathrm{NaCl}$ concentration in solution that sensed equivalent saltiness with sample gels. (A): setting at $30^{\circ} \mathrm{C}$ for $60 \mathrm{~min}$ followed by 90 for $30 \mathrm{~min}$ for "strong gel", (B) heating at $90^{\circ} \mathrm{C}$ for $30 \mathrm{~min}$ for "weak gel" and 1, 2, 3 are $\mathrm{NaCl}$ added into the sample in $\%(w / w)$. Open bars, closed bars: number of chews 10 and 20, respectively. Bars with the same alphabetical letter are not significantly different $(\mathrm{p}>0.05)$.

The perceived saltiness and saltiness efficiency ratio of heat-induced surimi gels prepared using different heating conditions (A and B) and 1,2 and $3 \%(\mathrm{w} / \mathrm{w}) \mathrm{NaCl}$ concentrations were evaluated after chewing 10 and 20 times (Figure 2). The perceived saltiness expressed $\mathrm{NaCl}$ concentration that was sensed as the equivalent saltiness with the sample gel was clearly different depending on the $\mathrm{NaCl}$ content.
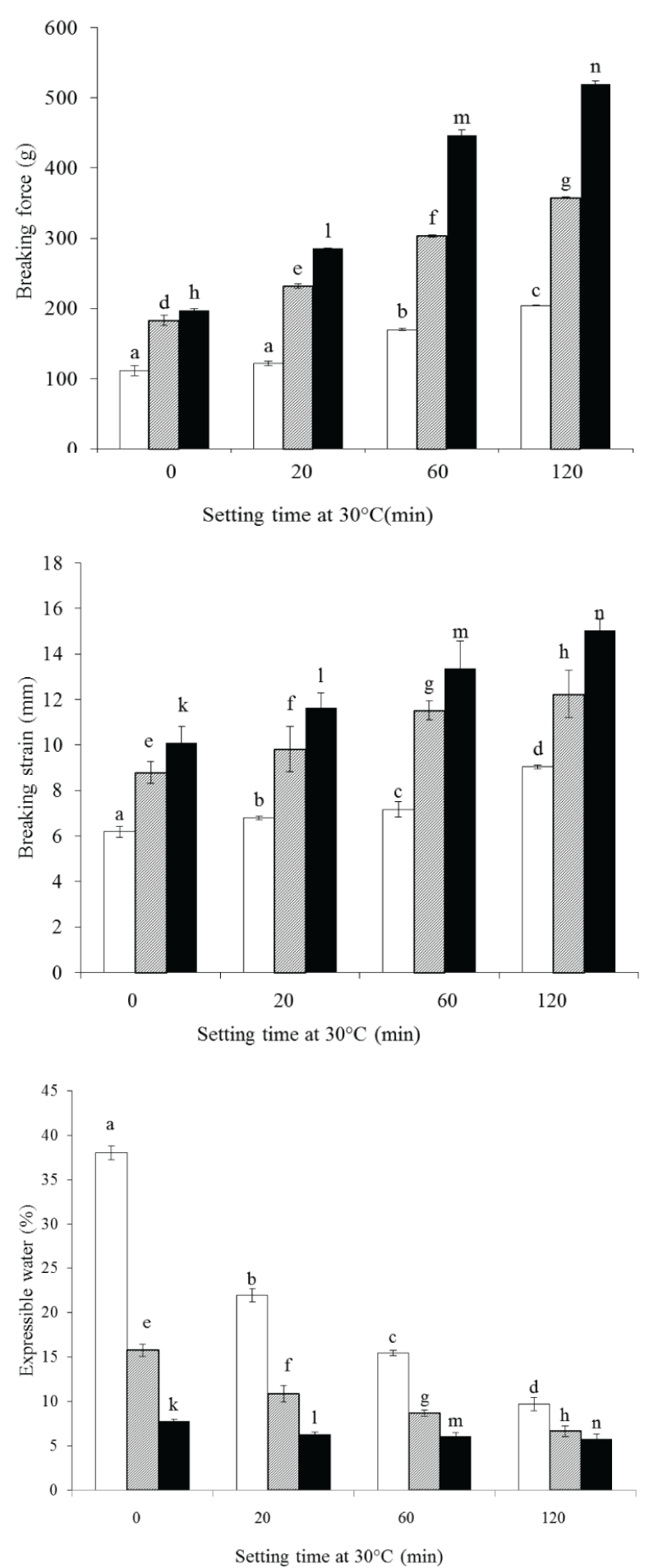

Figure 3: Physical properties and expressible water of 2-steps heated gels from washed surimi prepared with different setting time and $\mathrm{NaCl}$ addition. Mean and standard deviation of more than three measurements. Bars with the same alphabetical letter are not significantly different $(\mathrm{p}>0.05)$. Open, diagonal, and closed bars: 2 steps heated gels from washed surimi with 1,2 and $3 \%(w / w) ~ N a C l$, respectively. 
However, there were not significant differences in perceived saltiness ( $\mathrm{p}>0.05)$ between $\mathrm{A} 1$ and $\mathrm{B} 1, \mathrm{~A} 2$ and $\mathrm{B} 2, \mathrm{~A} 3$ and $\mathrm{B} 3$ gels. The perceived saltiness was from 0.21 to $0.82 \%$ while salt content in sample was $1-3 \%$. Data shows that the perceived saltiness level of surimi gels was very lower than actual salt content in surimi gel samples. This result was similar to the result of perceived sweetness of solid food. Shimada et al. [12] found that the perceived sweetness level of solid sweets was much lower than that of sucrose solutions. The sucrose content of each sample was from 7.8 to $80 \%$, while the perceived sweetness in terms of the sucrose solution was from 6.7 to $25.7 \%$. The overall correlation between the sucrose content and sweetness was 0.73 [12].

In this study, the average saltiness efficiency ratio was $0.19-0.26$. This means that the differences in the perceived saltiness of gels were relatively difficult to detect and were $1 / 4$ to $1 / 5$ of the actual $\mathrm{NaCl}$ content. These results suggested that the saltiness of heat-induced surimi gels was not affected by the gel strength (derived from different setting conditions).

Generally speaking, foods containing low taste materials exhibit high taste efficiency ratio and the ratio show high dependency on physical properties. [12,33-37]. Difficulties were salt in surimi gels as well as sucrose in gel-type confectionaries influence not only taste but also physical properties. Previous studies about sweetness of gel foods reported different phenomena. The sweetness of samples swallowed without chewing was greatly affected by the sucrose content, and the other samples were affected by such factors as hardness [12]. The sucrose released from agar gels was reported to decrease with increasing fracture stress and strain [38-40] and these observations were consistent with sensory perceived sweetness [33]. Unfortunately, it could not dissolve these complex relationships between saltiness, salt content, and physical properties of surimi gels.

On the other hand, the perceived saltiness was slightly higher after chewing 20 times than after chewing 10 times, although this difference was not significant. This result means that the evaluation with fixed number of chewing have some inconvenience, because the number of chews required for the evaluation of heat-induced gels differed depending on textural differences. It was assumed that the fixed number of chew is not appropriate method for the determination of the perceived saltiness differences in the gels having different texture. Accordingly, in the next step, the evaluation was conducted under free chewing conditions.

\section{Evaluation of perceived saltiness of washed surimi gel}

Although above-mentioned results suggested that the difference in gel strength of heat-induced surimi gels prepared with/without setting did not affect perceived saltiness, surimi additives such as sucrose, sorbitol, and polyphosphate were thought to influence the taste of heat-induced surimi gels. The proximate composition of frozen surimi was as follows: moisture $73.6 \%(\mathrm{w} / \mathrm{w})$, crude protein $19.8 \%(\mathrm{w} / \mathrm{w})$, crude lipid $0.5 \%(\mathrm{w} / \mathrm{w})$, crude ash $0.6 \%(\mathrm{w} / \mathrm{w})$, and crude carbohydrate $5.5 \%(\mathrm{w} / \mathrm{w})$. It was thought that the crude carbohydrate included sucrose and sorbitol. Therefore, in the next step, heat-induced gels were prepared with washed surimi to eliminate the effect of additives. After repeating of washing surimi, the residual content of sorbitol and sucrose became less than $0.4 \%$.

Furthermore, it was thought that an improved method for perceived saltiness evaluation was necessary. The amount of mastication required before swallowing differed depending on the texture of the samples, making it difficult to compare the perceived saltiness of samples using fixed number of chews. Unlike natural mastication, where more number of chews and longer duration were required for harder gels, the panelists were asked fixed numbers of chews in this study. They may control the chewing force; weak force per chew for weaker gels and stronger force for harder gels. Therefore, the evaluation was performed under free chewing conditions.
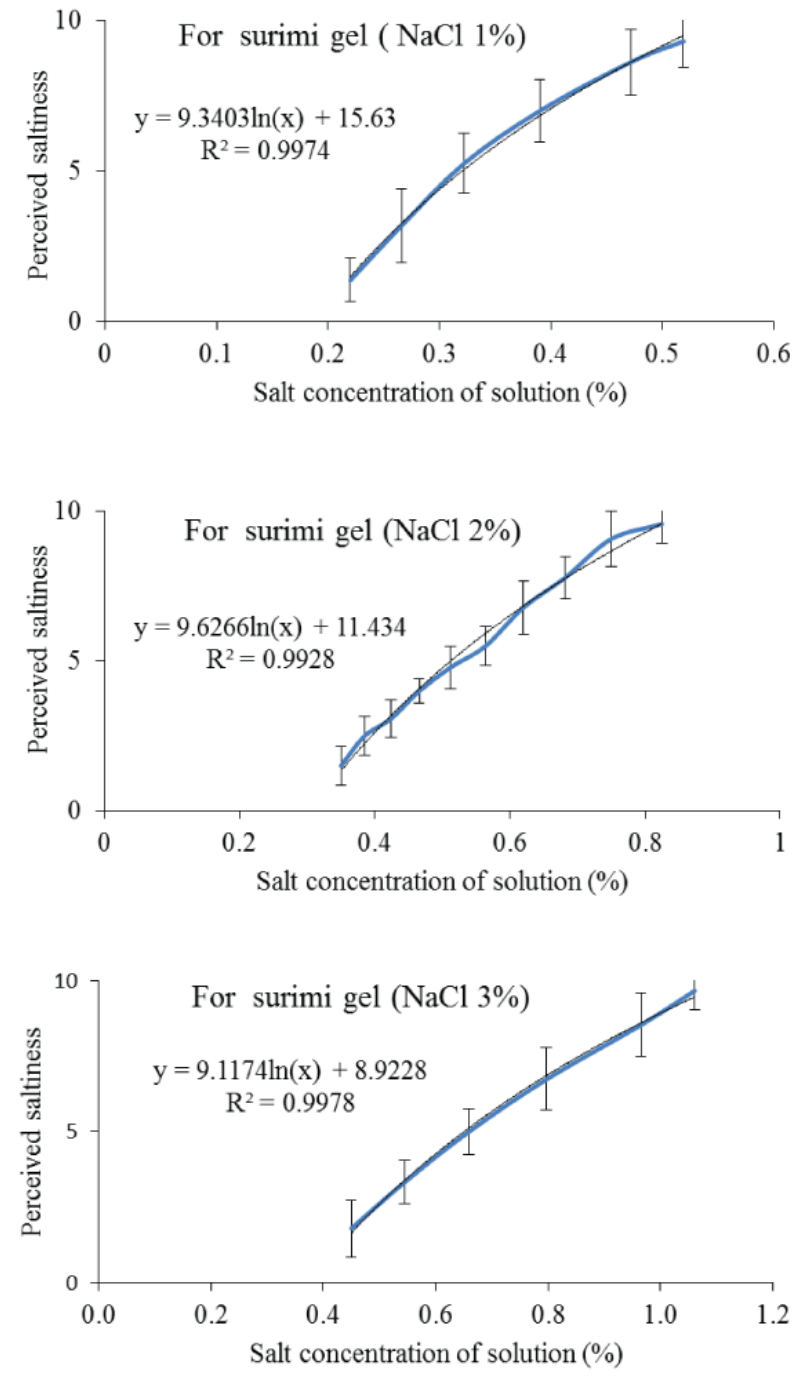

Figure 4: Perceived saltiness score of salt solution by trained panelists. Mean and standard deviation of 18 panelists. Equation in each graph is best fit curve of a logarithmic regression model with the regression coefficient.

Physical properties of washed surimi gels: The breaking properties and expressible water of washed surimi gels are shown in Figure 3. The physical properties of heat-induced gels differed considerably depending on the salt content and setting time. With an increase in the setting time, the breaking force increased especially in the case of the gel with $3 \% \mathrm{NaCl}$. The decrease in expressible drip accompanied by setting was remarkable especially in gels with low salt concentration (1\%). Maximum gel strength can be attained from a given surimi by 
Page 6 of 7

allowing for sufficient solubilization through proper comminution at an optimum salt concentration [41], and the gel strength increases depending on the salt content in the range of $0-3 \%$ [42]. Additionally, the gel strength and water holding capacity are almost corresponding in the range of this $\mathrm{NaCl}$ concentration [43].

The results obtained were almost matched to these studies. Consequently, it was shown that heat-induced gels with a variety of breaking properties and water holding capacity could be obtained by addition of $1-3 \% \mathrm{NaCl}$ and setting for $0-120 \mathrm{~min}$.

\begin{tabular}{|l|l|l|l|l|l|}
\hline \multirow{2}{*}{$\mathrm{NaCl}$} & \multirow{2}{*}{$\begin{array}{l}\text { Saltiness } \\
\text { Parameter }\end{array}$} & \multicolumn{4}{|l|}{ Setting time at $30^{\circ} \mathrm{C}(\mathrm{min})$} \\
\cline { 3 - 6 } & & $\mathbf{0}$ & $\mathbf{2 0}$ & $\mathbf{6 0}$ & 120 \\
\hline \multirow{2}{*}{$1 \%$} & $I_{\max }$ & $0.29^{\mathrm{a}}$ & $0.30^{\mathrm{a}}$ & $0.27^{\mathrm{a}}$ & $0.30^{\mathrm{a}}$ \\
\cline { 2 - 6 } & SER & $0.29^{\mathrm{d}}$ & $0.30^{\mathrm{d}}$ & $0.27^{\mathrm{d}}$ & $0.30^{\mathrm{d}}$ \\
\hline \multirow{2}{*}{$2 \%$} & $I_{\max }$ & $0.56^{\mathrm{b}}$ & $0.58^{\mathrm{b}}$ & $0.57^{\mathrm{b}}$ & $0.54^{\mathrm{b}}$ \\
\cline { 2 - 6 } & SER & $0.28^{\mathrm{d}}$ & $0.29^{\mathrm{d}}$ & $0.29^{\mathrm{d}}$ & $0.27^{\mathrm{d}}$ \\
\hline \multirow{2}{*}{$3 \%$} & $I_{\max }$ & $0.66^{\mathrm{c}}$ & $0.71^{\mathrm{c}}$ & $0.73^{\mathrm{c}}$ & $0.67^{\mathrm{c}}$ \\
\cline { 2 - 6 } & SER & $0.22^{\mathrm{d}}$ & $0.24^{\mathrm{d}}$ & $0.24^{\mathrm{d}}$ & $0.22^{\mathrm{d}}$ \\
\hline
\end{tabular}

Table 3: Maximum saltiness intensity $\left(I_{\max }\right)$ and saltiness efficiency ratio (SER) of 2-steps heated gels prepared from washed surimi with various setting time at $30^{\circ} \mathrm{C}$. Values are average of 9 trained panelists with 2 repetitions. Value followed by different alphabetical letters within a row indicate significant differences $(\mathrm{p}<0.05)$.

\begin{tabular}{|c|c|c|c|}
\hline $\begin{array}{l}\text { Maximum saltiness } \\
\text { intensity of washed } \\
\text { surimi gel }\end{array}$ & $\begin{array}{l}\text { Breaking } \\
\text { force }\end{array}$ & $\begin{array}{l}\text { Breaking } \\
\text { strain }\end{array}$ & $\begin{array}{l}\text { Expressible } \\
\text { water }\end{array}$ \\
\hline $1 \%(w / w) \mathrm{NaCl}$ & 0.01 & 0.08 & 0.01 \\
\hline $2 \%(\mathrm{w} / \mathrm{w}) \mathrm{NaCl}$ & 0.03 & 0.24 & 0.11 \\
\hline $3 \%(w / w) \mathrm{NaCl}$ & 0.03 & 0.03 & 0.26 \\
\hline
\end{tabular}

Table 4: Correlation coefficient $(r)$ between maximum saltiness intensity of washed surimi gel and breaking force, breaking strain, and expressible water.

Sensory evaluation of washed surimi gels: Figure 4 shows the perceived saltiness of salt solution. A good logarithmic relationship was obtained between salt content in solution and perceived saltiness by panelists. Using those regression models, the saltiness score evaluated by free chewing was converted to $\mathrm{NaCl}$ concentration of $\mathrm{NaCl}$ solution sensed equivalent saltiness. Table 3 shows the maximum saltiness intensity $\left(I_{\max }\right)$ of heat-induced gels from washed surimi, which were prepared with different setting times $(0,20,60,120 \mathrm{~min})$ and $\mathrm{NaCl}$ contents $(1 \%, 2 \%$ and $3 \%)$. The perceived saltiness was different depending on the $\mathrm{NaCl}$ content, but not on the setting time. $I_{\max }$ were approximately the same to saltiness of $0.25 \%, 0.5 \%$ and $0.7 \%$ $\mathrm{NaCl}$ solutions for gels including $1 \%, 2 \%$ and $3 \% \mathrm{NaCl}$, respectively. The saltiness efficiency ratios (SER) calculated from $I_{\max }$ were 0.22-0.30 for all gels. These results were consistent with the previous results obtained using heat-induced surimi gels. The linear correlation coefficient (r) between $I_{\max }$ and breaking force, breaking strain, and expressible water of washed surimi gels were shown in Table 4. It was clearly presented that all $r$ values were low. It means that there are no significant relationship between $I_{\max }$ and breaking force, breaking strain, and expressible water of washed surimi gels prepared with different setting times. The sensory evaluation results obtained during free mastication revealed that the differences in physical properties derived from the setting time had minimal effects on the perceived saltiness during gel consumption.

\section{Conclusions}

In both the case of heat-induced gels prepared from surimi and washed surimi by various setting time, the physical properties were very different depending on the heating conditions. On the other hand, the differences of physical properties did not affect the saltiness efficiency ratio of the gels. This phenomenon may be influenced by not only the characteristics of the texture derived by setting but also the salt concentration in the gels. For this reason, it should be carefully judged whether the texture will affect the saltiness efficiency of the surimi products. Therefore, further studies are required to clarify what kind of physical factors affect the taste of surimi-based products.

\section{Acknowledgement}

The authors kindly thank Vietnamese Government through the Ministry of Agriculture and Rural Development and Vietnam International Education Development-Ministry of Education and Training for awarding scholarship to Thi My Hanh Tran. The authors would like to thank all sensory panelists from Tokyo University of Marine Science and Technology (TUMSAT).

\section{References}

1. World Health Organization (2006) Reducing salt intake in populations, Paris, France.

2. Ruusuen M, Puolanne E (2005) Reducing sodium intake from meat products. Meat Science 70: 531-541.

3. Desmond E (2006) Reducing salt: A change for the meat industry. Meat Science 74: 188-196.

4. World Health Organization (2007) Reducing salt intake in populations, Geneva, Switzerland.

5. Department of Agriculture and Department of Health and Human Services (2010), USA.

6. The National Institute for Health and Clinical Excellence (2015) Dementia, disability and frailty in later life-mid-life approaches to delay or prevent onset.

7. National Health and Medical Research Council (NHMRC) Annual Report (2006-2007), Australia Government.

8. The Japanese Society of Hypertension (2009) Guideline for Hypertension Treatment. Hypertension Research 32: 4-107.

9. Standard Tables of Food Composition in Japan (2010) Ministry of Education, Culture, Sports, Science and Technology, Japan.

10. Yoshinod M (1995) Recent advances in the understanding of egg white protein functionality. Trends in Food Science and Technology 6: 225-232.

11. Garcés-Rimón M, Sandoval M, Molina E, López-Fandiño R, Miguel M (2016) Egg protein hydrolysates: New culinary textures. Int J Gastr Food Sci 3: 17-22.

12. Shimada A, Hatae K, Shimada A (1990) Sweetness perception of solid food. J Home Econ Jpn 41: 137-142.

13. Yang K, Wang Z, Tom Brenner, Kikuzaki H, Nishinari K, et al. (2015) Sucrose release from agar gels: Correlation with sucrose content and rheology. Food Hydrocolloids 43: 132-136.

14. Mosca AC, van de Velde F, Bult JHF, van Boekel MAJS, Stieger M (2010) . Food Quality and Preference 21: 837-842. 
Citation: Tran TMH, Kohyama K, Watanabe N, Osako K, Okazaki E (2017) Relationship between the Physical Properties and Perceived Saltiness of Various Surimi Gels Prepared by Different Setting Conditions. J Exp Food Chem 3: 124. doi:10.4172/2472-0542.1000124

Page 7 of 7

15. Shimizu S, Matubayasi M (2014) Gelation: the role of sugars and polyols on gelatin and agarose. J Phys Chem 118:13210-13216.

16. Hosseini-Shekarabi SP, Hosseini SE, Soltani M, Kamali A, Valinassab T (2015) Effect of heat treatment on the properties of surimi gel from black mouth croaker. Int Food Res J 22: 363-371

17. Park JW (2014) Surimi and surimi seafood, CRC Press ( $3^{\text {rd }}$ edn), 666p.

18. AOAC (1999) Official Methods of Analysis. Association of Official Analytical Chemists. Washington, DC.

19. Bradstreet RB (1954) Kjeldahl method for organic nitrogen. Anal Chem 26: 185-187.

20. Folch J, Lees M, Sloane SGH (1957) A simple method for the isolation and purification of total lipids from animal tissues. J Biol Chem 226: 497-509.

21. UV-method for the determination of Sucrose, D-Glucose in foodstuffs, beverages and other materials. Cat. No. 10139041 035, R-BIOPHARMEnzymatic BioAnalysis and Food Analysis.

22. Colorimetric method for the determination of D-sorbitol and xylitol in foodstuffs and other materials. Ca. No. 10670057 035, R-BIOPHARMEnzymatic BioAnalysis and Food Analysis

23. Joint FAO/WHO Food Standards Programme, Codex Alimentarius Commission.

24. Jafarpour A, Gorczyca EM (2009) Rheological characteristics and microstructure of common carp (Cyprinus carpio) surimi and kamaboko gel. Food Biophys 4: 172-179.

25. ISO 8586:2012. Sensory analysis-General guidelines for the selection, training and monitoring of selected assessors and expert sensory assessors.

26. PanelCheck User Manual (2009).

27. Shimizu Y, Machida R, Takenami S (1981) Species variations in the gelforming characteristics of fish meat paste. Nippon Suisan Gakkaishi 47: 95-104.

28. Niwa E, Nowsad AA, Kanoh S (1991) Comparative studies on the physical parameters of kamabokos treated with the low temperature setting and high temperature setting. Nippon Suisan Gakkaishi 57: 105-109.

29. Yongsawatdigul J, Park JW (2004) Gelation of threadfin bream surimi as affected by thermal denaturation, transglutaminase and proteinase(s) activities. Develop Food Sci 42: 343-356.

30. Niwa E (1985) Functional aspect of surimi. In Martin RE, Collete RL (Eds). Proceedings of the International Symposium on Engineered
Seafood Including Surimi, pp. 141-147. National Fisheries Institute. Washington: DC.

31. Van Phu N, Morioka K, Itoh Y (2010) Microstructure of white croaker surimi protein gels set at low temperature under the inhibition of the polymerization and degradation of protein. J Biol Sci 10: 499-506.

32. Horio T, Kawamura Y (1989) Effects of texture of food on chewing patterns in the human subject. J Oral Rehabil 16: 177-83.

33. Kohyama K, Hayakawa F, Kazami Y, Nishinari K (2016) Sucrose release from agar gels and sensory perceived sweetness. Food Hydrocolloids 60: 405-414.

34. Clark R (2002) Influence of hydrocolloids on flavour release and sensoryinstrumental correlations. In Gums and Stabilizers for the Food Industry 11 (Phillips GO and Williams PA, eds.) pp. 217-224. Royal Society of Chemistry, Cambridge, MA.

35. Morris ER (1993) Rheological and organoleptic properties of food hydrocolloids. In Food Hydrocolloids, Structures, Properties, and Functions (Nishinari K and Doi E, eds.) pp. 201-210. Plenum Press, New York, NY.

36. Nishinari K, Fang Y (2016) Sucrose release from polysaccharide gels e a review. Food Func 7: 2130-2146.

37. Moritaka H, Naito S (2002) Agar and gelatin gel flavor release. J Text Stud 33: 201-214

38. Wang Z, Yang K, BrennerT, Kikuzaki H, Nishinari K (2014) The influence of agar gel texture on sucrose release. Food Hydrocolloids 36: 196-203.

39. Yang K, Wang Z, Brenner T, Kikuzaki H, Fang Y, et al. (2015) Sucrose release from agar gels: effects of dissolution order and the network inhomogeneity. Food Hydrocolloids 43: 100-106.

40. Yang K, Wang Z, Brenner T, Kikuzaki H, Fang Y, et al. (2015) Sucrose release from agar gels: correlation with sucrose content and rheology. Food Hydrocolloids 43: 132-136.

41. Chong ML, Wu MC, Okada M (1992) Ingredient and Formulation Technology for Surimi-Based Products, Surimi Technology, Marcel Dekker inc, 273-302.

42. Shimizu Y, Simidu W (1955) Studies on jelly strength of Kamaboko-IX. On influence of salts-sodium chloride. Bulletin of the Japanese Society for the Science of Fish 21: 501-502.

43. Akahane Y, Shimizu Y (1989) Effect of pH and sodium chloride on the water holding capacity of surimi and its gel. Nippon Suisan Gakkaishi 55: 1827-1832. 